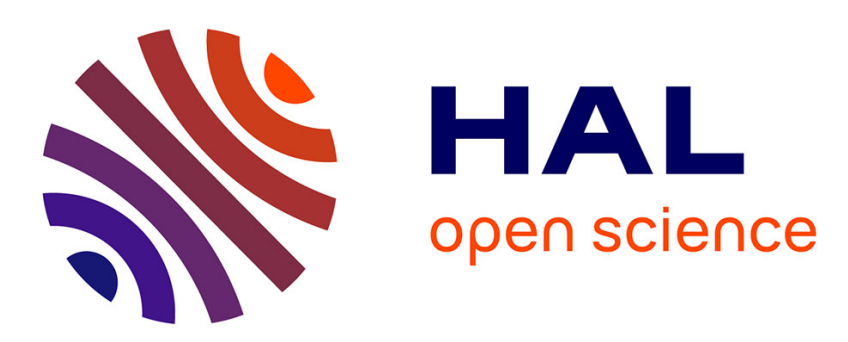

\title{
Research on Spatial Variability Characteristics of Black Soil Unfrozen Water in Songnen Plain during Freezing-Thawing Period
}

\author{
Zilong Wang, Qiang Fu, Jun Meng, Qiuxiang Jiang, Xianghao Wang
}

\section{To cite this version:}

Zilong Wang, Qiang Fu, Jun Meng, Qiuxiang Jiang, Xianghao Wang. Research on Spatial Variability Characteristics of Black Soil Unfrozen Water in Songnen Plain during Freezing-Thawing Period. 8th International Conference on Computer and Computing Technologies in Agriculture (CCTA), Sep 2014, Beijing, China. pp.193-199, 10.1007/978-3-319-19620-6_24 . hal-01420232

\section{HAL Id: hal-01420232 https://hal.inria.fr/hal-01420232}

Submitted on 20 Dec 2016

HAL is a multi-disciplinary open access archive for the deposit and dissemination of scientific research documents, whether they are published or not. The documents may come from teaching and research institutions in France or abroad, or from public or private research centers.
L'archive ouverte pluridisciplinaire HAL, est destinée au dépôt et à la diffusion de documents scientifiques de niveau recherche, publiés ou non, émanant des établissements d'enseignement et de recherche français ou étrangers, des laboratoires publics ou privés.

\section{(c)(1)}

Distributed under a Creative Commons Attribution| 4.0 International License 


\title{
Research on Spatial Variability Characteristics of Black Soil Unfrozen Water in Songnen Plain during Freezing-Thawing Period
}

\author{
Zilong Wang ${ }^{1,2,3,4, a}$, Qiang $\mathrm{Fu}^{1,2,3}$, Jun Meng ${ }^{4}$, Qiuxiang Jiang ${ }^{1,2,3,4}$, Xianghao Wang ${ }^{1}$ \\ ${ }^{1}$ College of Water Conservancy and Architecture, Northeast Agricultural University, Harbin \\ $150030 ;{ }^{2}$ Collaborative Innovation Center of Grain Production Capacity Improvement in \\ Heilongjiang Province, Harbin $150030 ;{ }^{3}$ Key Laboratory of Water-saving Agriculture, College \\ of Heilongjiang Province, Harbin 150030; ${ }^{4}$ Postdoctoral Mobile Research Station of \\ Agricultural and Forestry Economy Management, Northeast Agricultural University, Harbin \\ 150030 \\ awzl1216@163.com.cn
}

\begin{abstract}
To address the difficulties of the complexity and the quantitative description of spatial non-homogeneity in the process of freezing and thawing of soil moisture migration, taking the unfrozen water as the research object, and using geostatistics to study the spatial variability characteristics of unfrozen soil water in different freezing and thawing stages. The results show that different freezing and thawing stages of unfrozen soil water has good spatial structure and strong spatial correlation, and it has a strong spatial redistribution effect on soil moisture. The application of geostatistics provides a new train of thought for in-depth study on freezing-thawing process of soil moisture transport mechanism.
\end{abstract}

Keywords: Songnen Plain, black soil, soil unfrozen water, spatial variability

\section{$1 \quad$ Introduction}

Freezing and thawing of soil water movement, as an important part of the water cycle in nature, agriculture, water resources, environmental engineering, which occupies an extremely important position. To carry on an in-depth investigation into the variations of the freezing and thawing period soil moisture, master the laws of its motion, will not only help to promote the development of the theory of soil water dynamics, but also provide the theoretical basis for water resources accurately evaluation, efficient utilization of soil water, and a reasonable determination of farmland irrigation technical parameters, etc [1].

Study on the theory of soil water dynamics have made considerable progress, along with the changes of soil moisture from the morphology point of view to the energy state theory [2],the research methods also vary from the qualitative description [3-4] based on soil physics test to the quantitative research [5-6] based on the numerical simulation. However, dramatic phase transitions and spatial variability of soil moisture in the freezing thawing process, that lead to the existing methods in the analysis of soil moisture variation during freezing and thawing period insufficient. 
Geostatistics is a theory, which study on the spatial variability of the properties of a system. The theory has been applied in the study on spatial variability of in unfreezing soil water [7].But it has fewer applications on the freezing and thawing soil moisture variation.

Therefore, in this paper, the methods of geostatistics were used to analysis the spatial variability of black unfrozen soil water in Songnen Plain in the freezingthawing period, expecting to provide scientific basis for reasonable regulation and utilization of black soil water in Songnen Plain.

\section{Materials and Methods}

\subsection{Study Area and Test Scheme}

Field experiments were measured in a place of dry land in the city of Harbin, soil type is black soil. Harbin city is located in the southeast of Songnen Plain, has a temperate continental monsoon climate with its severe cold winter, dry and windy spring, has no perennial frozen soil layer, the annual average temperature is $3.6^{\circ} \mathrm{C}$, the average January temperature is $-20.3^{\circ} \mathrm{C}$, the average frost free period is 141 days, the average annual precipitation is $523.3 \mathrm{~mm}$, the average annual snowfall is $63.1 \mathrm{~mm}$, the annual average frost depth is about $1.75 \mathrm{~m}$.

Field experiment treats the soil unfrozen water in freezing-thawing stages as the observation object, and uses TRIME-T3 time domain reflectometry to monitor soil unfrozen water during the soil thawing period of 2008 to 2009. In the same vertical profile every $2 \mathrm{~m}$ buried 1 TDR probe, altogether 10 probes was buried, each TDR probe sets 8 measuring points, respectively $20 \mathrm{~cm}, 40 \mathrm{~cm}, 60 \mathrm{~cm}, 80 \mathrm{~cm}, 100 \mathrm{~cm}, 140 \mathrm{~cm}$, $180 \mathrm{~cm}, 220 \mathrm{~cm}$ and $260 \mathrm{~cm}$.

\subsection{Research Methods}

Geostatistics is the most important method to study the spatial variability characteristics of soil. Since 1963, the famous French statistician Matheron G has put forward the concept of geostatistics [8], through decades of development, geostatistics has been widely applied in soil science, ecology, geology, hydrology, meteorology, environment and many other fields.

Since geostatistics methods and theory can not only keep the autocorrelation of space variables, but also can make the simulation value of measured point be equal to the measured value, it can use a few sampling point to simulate many unknown information and spatial distribution, which greatly reduced the field sampling and observed workload, enhanced visibility [9] of data analysis.

\section{$3 \quad$ Results and Analysis}




\subsection{Semivariance Analysis}

Based on the soil unfrozen water content observational data in different freezingthawing stages, using the software of GS +7 for the semi variance analysis, as shown in Table 1.

Table 1. Semivariance analysis of soil unfrozen water content in different freezing-thawing stages

\begin{tabular}{ccccccc}
\hline Date & $\begin{array}{c}\text { Fitting } \\
\text { model }\end{array}$ & Nugget & Sill & $\begin{array}{c}\text { Nugget/Sill } \\
(\%)\end{array}$ & $\begin{array}{c}\text { Range } \\
(\mathrm{m})\end{array}$ & $R^{2}$ \\
\hline $08-12-19$ & Sphere & 0.228 & 1.323 & 17.2 & 14.41 & 0.827 \\
$09-01-10$ & Sphere & 0.001 & 1.443 & 0.1 & 14.8 & 0.899 \\
$09-03-16$ & Sphere & 0.001 & 1.41 & 0.1 & 14.2 & 0.876 \\
$09-03-27$ & Sphere & 0.001 & 1.392 & 0.1 & 13.91 & 0.873 \\
$09-04-23$ & Sphere & 0.216 & 1.081 & 20.0 & 9.82 & 0.737 \\
$09-05-19$ & Sphere & 0.238 & 1.078 & 22.1 & 6.47 & 0.912 \\
\hline
\end{tabular}

Results of the Semi variance analysis of soil unfrozen water content in different freezing-thawing stages in the experimental areas show that: soil unfrozen water content in different freezing-thawing stages has good spatial structure, their theoretical semivariogram models were all spherical model, as the same as the theoretical semivariogram models of unfrozen soil total water content in different freezing-thawing stages in previous research [10]. The spatial structure of the soil moisture test area should adopt the spherical model to describe. Model fitting precision is lower than the total soil moisture content's, but still can meet the precision requirement. As is shown from the unfrozen soil water content Nugget/Sill in different freezing-thawing stages, the spatial correlation of most unfrozen soil water content is stronger than the corresponding position of the unfrozen soil water content [11].

According to the horizontal time span comparison, the spatial correlation of the initial freezing period (December 19, 2008) and the melt season (April 23 and May 19, 2009 ) is relatively weak. Soil has strong spatial correlation in stable freezing period. Effect of freezing process on soil unfrozen water content spatial correlation was in contrast to the situation in soil water content.

Investigation of the range of soil unfrozen water content: range of soil unfrozen water content in every freezing stages of the freezing period (before April 23, 2009) was about $14 \mathrm{~m}$, the range of melting period decreased by $50 \%$.It shows that the freezing-thawing processes also have impact on the spatial correlation distance of unfrozen soil water content, but relatively small.

\subsection{Analysis of Spatial Variation Characteristics}

Using the Geostatistical Analyst module in ArcGIS 9 Software to carry on the spatial local estimation of the unfrozen soil water content in different freezing-thawing stages and to map the spatial distribution, as shown in Fig.1.The left side data in the spatial distribution of the unfrozen soil water content in different stages in Fig.1 represents 
the depth of the measuring points, the unit is $\mathrm{cm}$; the upper marks represents each TDR probe.

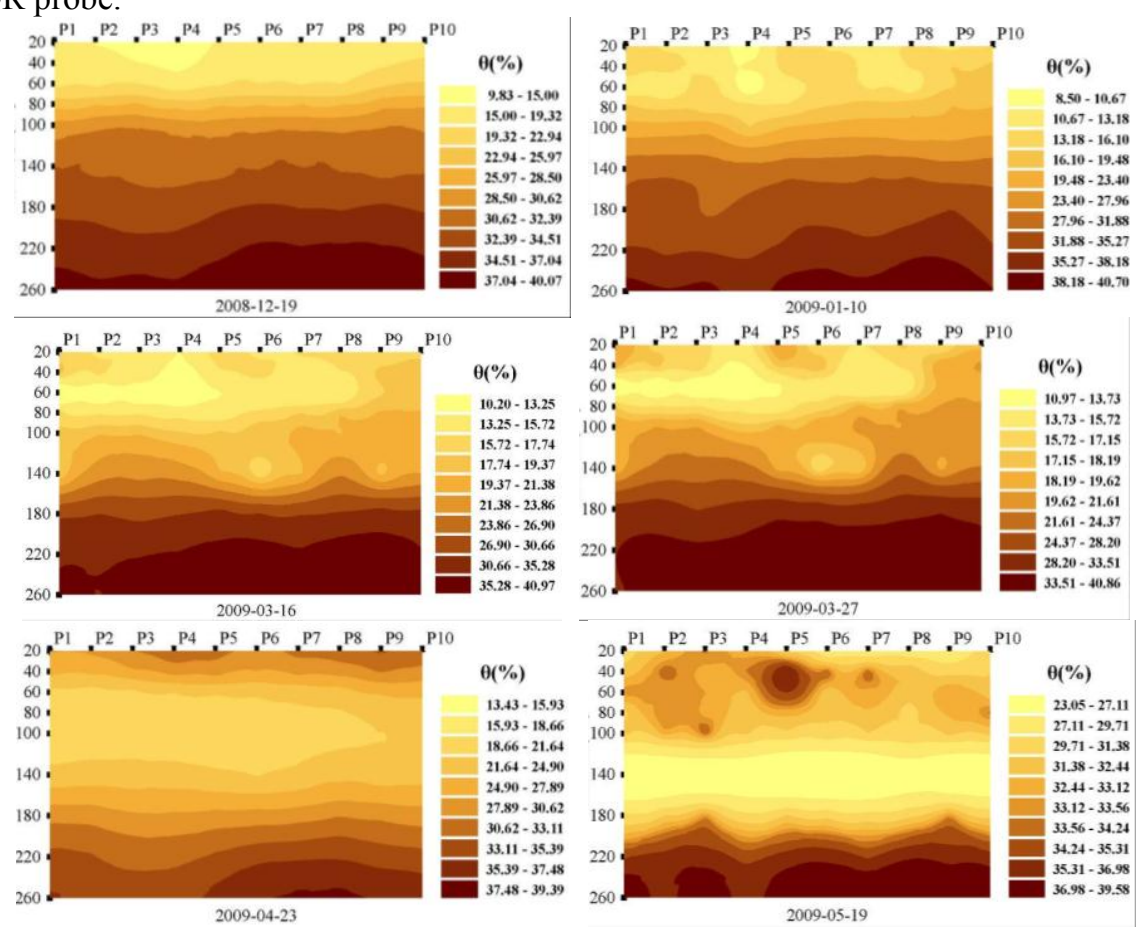

Fig.1. Spatial distribution maps of soil unfrozen water content in different freezing-thawing stages

From Fig. 1 we can see, in the process of freezing-thawing stages, the two dimensional spatial distribution of the unfrozen soil water content in the profile has certain regularity. The unfrozen soil water content and soil the negative temperature has an extremely close relationship [12-13]. In December 19, 2008, the soil belongs to the initial freezing period, freezing depth is $65 \mathrm{~cm}$, the equivalent zone of soil unfrozen water content present banded rules, it shows that the phase change process of water plays an important role in the redistribution of soil moisture. For the part above $60 \mathrm{~cm}$ measuring point in the freezing layer and the part below $100 \mathrm{~cm}$ measuring point in the unfrozen layer, the banded equivalent zone of soil unfrozen water content is wide, that is to say soil unfrozen water in these region changes little in the vertical direction. However, the equivalent zone of soil unfrozen water content at the measuring points between $60 \mathrm{~cm}$ and $100 \mathrm{~cm}$ is narrow, it changes heavily in the vertical direction. Because of the existence of soil freezing front, the unfrozen soil water below the location of the freezing front migrate to the frozen zone, this phenomenon dovetails the fact of the freezing depth of $65 \mathrm{~cm}$.

Based on the same principle, the freezing depth is about $100 \mathrm{~cm}$ in January 10 , 2009, 160 cm in March 16, 2009, and in March 27, 2009 the freezing depth reached the maximum $162 \mathrm{~cm}$, in the adjacent soil layer below measuring points for $100 \mathrm{~cm}$ and the soil layer between $140 \mathrm{~cm}$ to $180 \mathrm{~cm}$ between the unfrozen water content 
dramatic changes in the vertical direction, which were associated with the development of freezing depth or the depth of the freezing front, that's to say that the drastic change in the vertical direction of soil unfrozen water content in each frozen stages was caused by soil freezing. Therefore, the location of the freezing soil can be inferred according to the spatial distribution chart of the soil unfrozen water content in the freezing period. The unfrozen soil water content in freezing period showed a trend of increasing gradually from top to bottom. At the same time, notably in the freezing period of soil, for the frozen layer, the spatial distribution of the unfrozen water content presents regularly banded structure as the same as in the initial freezing period. It shows that when the soil is frozen, the unfrozen water content decreases rapidly, and continues to decline with the temperature's further reducing, but the freezing effect on the movement of the unfrozen water in frozen layer is small, the possible reasons to this question mainly are the atmospheric environmental conditions, the boundary of micro topography and the spatial variability of the soil water conductivity characteristics.

For the soil thawing period, the soil began to melt from two directions [14-15], while the soil unfrozen water content also increased from two directions. The spatial distribution situation of the soil unfrozen water content in the whole soil profile in April 23 and May 19, 2009 were shown in Fig.1. Frozen soil region is the low value area of unfrozen water content in soil, such as the measuring point between $40 \mathrm{~cm}$ to $140 \mathrm{~cm}$ in April 23, 2009 and the measuring point between $100 \mathrm{~cm}$ to $140 \mathrm{~cm}$ in May 19, 2009. At the same time, according to the spatial distribution of soil unfrozen water content in soil thawing period melting position between the upper and lower soil layer could be roughly inferred. For the soil surface in melting period, the initial melting period was the main driving force for migration of the unfrozen soil water content. Thus, the distribution of the soil surface unfrozen water content was regularly banded, and so was the situation in initial soil melting period. The soil unfrozen water content showed strong spatial variability after the surface soil began to thaw for a period of time. This is because in this period soil unfrozen water content is mainly affected by the different position of soil evaporation and the spatial variability of the water conductivity characteristics [16]. The lower soil also melted, but was less affected by external factors, so the unfrozen water content showed no spatial variability characteristics.

In order to analyze the severity that the different soil unfrozen water content vary with time in soil freezing-thawing period, spatial distribution maps of soil unfrozen water content coefficient of variation were drawn, as shown in Fig.2.

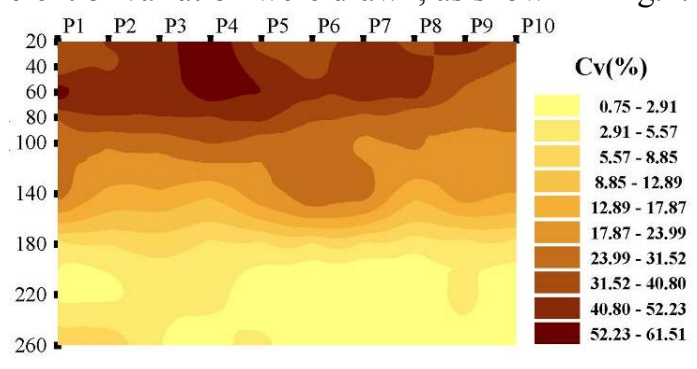


Fig.2. Spatial distribution map of coefficients of variation of soil unfrozen water content in freezing-thawing period

We can see from Fig.2, during the whole freezing-thawing period, coefficient of variation of the upper layer of the soil unfrozen water content is large, the lower layer of the soil unfrozen water content on the contrary. This is due to the upper layer of the soil unfrozen water content is not only the influence of the freezing-thawing effect, but also restricted by other factors. The coefficient of variation of bottom soil unfrozen water content is very small, below $5.57 \%$. The phase change of the soil moisture in freezing period did not occur in this part of soil layer, so there were many other factors that bring about the slight variation of its soil unfrozen water content with time changes.

\section{Conclusions}

Different stages of freezing and thawing soil not frozen water content has good spatial structure and strong spatial correlation, but has relatively small influence on the spatial correlation distance of the soil unfrozen water content. In the whole process of freezing-thawing, the severe variation of soil water content in vertical direction happened in the position of soil freezing front. The spatial distribution of soil unfrozen water content was mainly influenced by the effect of freezing-thawing in the initial freezing-thawing period, and was influenced by the environment and the variability of the soil itself in the late period of freezing-thawing period.

Using geostatistical theory and method is a good way to analyze different stages of freezing-thawing soil spatial variation features of unfrozen water content, also can visually depict the spatial distribution state's variation of soil unfrozen water content in different freezing-thawing period, at the same time, it can infer the freezingthawing position and the variability of the whole soil profile according to the spatial distribution of the unfrozen soil water content in the freezing-thawing period, so as to provides a new thought and method for further research on soil moisture migration mechanism of Songnen plain's black soil region at the freezing-thawing period.

\section{Acknowledgment}

The study was supported by the National Natural Science Foundation of China (51209039, 51279031), Specialized Research Fund for the Doctoral Program of Higher Education (20122325120016), China Postdoctoral Science Foundation (2012T50321, 2011M500632), Program for New Century Excellent Talents in University, Science Foundation for Distinguished Young Scholars of Heilongjiang Province (JC201402), Natural Science Foundation of Heilongjiang Province (E201241), Foundation of Heilongjiang Educational Committee (12521016), Heilongjiang Postdoctoral Fund (LBH-Z11231) and Doctoral Foundation of Northeast Agricultural University (2012RCB13). 


\section{References}

1. Cheng Guodong. Recent Development of Geocryological Study in China [J]. Acta Geographica Sinica, 1990, 45(2): 220-223.

2. Lei Zhidong, Yang Shixiu, Xie Senchuan. Soil water dynamics [M]. Beijing: Tsinghua University Press, 1988.

3. Bloomsberg G L and Wang S J. Effect of Moisture Content on Permeability of Frozen Soils [C]. Proc. American Geophysical Union Pacific Northwest Regional Meeting. Portland, OR. Oct. 1969, 16-17.

4. Qiu Guoqing, Wang Yaqing. Freezing Point of Loess in Lanzhou, China[J]. Journal of Glaciology and Geocryology, 1990, 12(2): 105-115.

5. Shoop S A and Bigl S R. Moisture Migration during Freeze and Thaw of Unsaturated Soils: Modeling and Large Scale Experiments [J]. Cold Regions Science and Technology, 1997, 25(1): 33-45.

6. Zheng Xiuqing, Fan Guisheng. Numerical Emulation on Simultaneous Soil Moisture and Heat Transfer under Freezing and Thawing Conditions [J]. Journal of System Simulation, 2001, 13(3): 308-311.

7. Jiang Qiuxiang, Fu Qiang, Wang Zilong. Research on Spatial Variability of Soil Water Characteristics In Western Semi-arid Area of Heilongiiang Province [J]. Journal of Soil and Water Conservation, 2007, 21(5): 118-122.

8. Matheron G. Principles of Geostatistics [J]. Economic Geology, 1963, 58: 1246-1266.

9. Chen Yaxin, Shi Haibin, Wei Zhanmin. Forecast Theory and Conditional Simulation of Soil Water and Salt Information's Spatial Variability [M]. Beijing: Science Press, 2005.

10. Wang Zilong, Fu Qiang, Jiang Qiuxiang, Li Tianxiao, Wang Xiaowei. Spatial Variability of Soil Moisture Profile in Seasonal Frozen Soil Region in Different Stages [J]. Scientia Geographica Sinica, 2010, 30(5): 772-776.

11. Cambardella C A, Moorman T B, Novak J M, et al. Field-scale Variability of Soil Properties in Central Iowa Soils [J]. Soil Sci. Soc. Am. J. 1994, 58: 1501-1511.

12. Xu Xuezu, Deng Yousheng. Experimental Study on Water Migration in Frozen Soil [M]. Beijing: Science Press, 1991.

13. Zhou Youwu, Guo Dongxin, Qiu Guoqing. Chinese Frozen Soil [M]. Beijing: Science Press, 2000.

14. Guo Zhanrong, Jin Enchun. Analysis on the characteristics of soil moisture transfer during freezing and thawing period [J]. Advances in Water Science, 2002, 13(3): 298-302.

15. Siberia Branch of the Soviet Academy of Sciences Institute of frozen soil. General Geocryology [M]. Beijing: Science Press, 1988.

16. Shi Chengxi, Li Songhao. Agricultural Hydrology [M]. Beijing: Agriculture Press, 1984. 